\title{
Malentendidos en Educación Infantil
}

\section{Misunderstanding in childhood education}

\author{
Cristóbal Gómez Mayorga*
}

Recibido: 11 de abril de 2020 Aceptado: 11 de abril de 2020 Publicado: 31 de julio de 2020

To cite this article: Gómez Mayorga, C. (2020). Malentendidos en Educación Infantil. Márgenes, Revista de Educación de la Universidad de Málaga, 1 (2), 172-174

DOI: https://dx.doi.org/10.24310/mgnmar.v1i2.8541

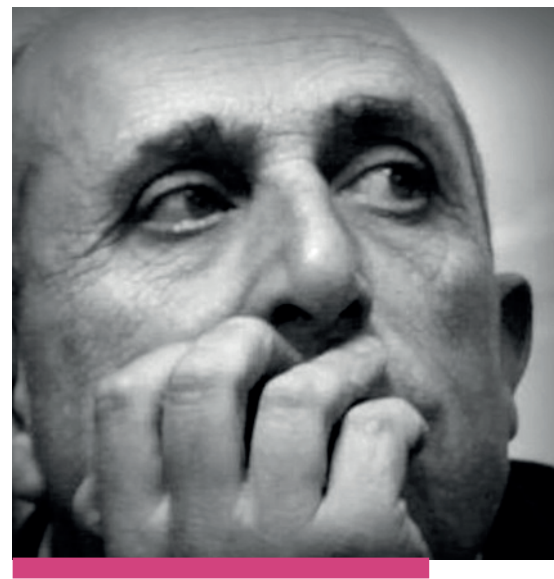

Cristóbal Gómez Mayorga

\section{RESUMEN}

Hay ciertos malentendidos en la educación infantil que es necesario volver a pensar cada poco. El autor apunta a algunos de estos asuntos, como el papel de las familias o el de la evaluación, ofreciéndonos argumentos para la reflexión.

Palabras clave: educación infantil; familia; función del profesorado; currículum; evaluación

\section{ABSTRACT}

There are certain misunderstandings in childhood education that need to be rethought time and time again. The author points to some of these issues, such as the role of families and assessment, offering us arguments for reflection.

Keywords: childhood education; family; role of teachers; curriculum; assessment

Nadie duda que la Educación Infantil es la etapa más importante de la vida. En estos primeros años se aprende a hablar, a pensar, a ser autónomo, se desarrolla la identidad, se establece las primeras relaciones sociales entre iguales y se incorpora los contenidos básicos de nuestra cultura. Pero hay ciertos malentendidos en este tiempo de aprendizaje sobre los que debemos reflexionar.

Entre el profesorado, la familia y la infancia hay un triángulo en continuo equilibrio que hoy está desdibujado. La vida va tan deprisa, es todo tan plástico y moldeable que hemos perdido los vértices de las figuras geométricas que dan seguridad y soporte a la estructura generacional. Comprender a la infancia no es pensar como niños y niñas de pocos años. Responder a sus demandas no es darles lo que piden sino ofrecerles lo que necesitan. Y los chicos y chicas de la pri- 


\section{H I S T O R I A S M Í N I M A S}

mera infancia necesitan pocas cosas pero esenciales: posibilidades de desarrollo, seguridad, límites y amor. Los padres, madres y profesorado siempre debemos estar en la base del triángulo en continua colaboración. No podemos formar una figura geométrica en la que el adulto esté al mismo nivel de quienes aún no tiene experiencia. Los mayores debemos comprender las necesidades de la infancia pero nunca acceder a sus exigencias derramadas. A los adultos nos toca ser el sostén de este triángulo.

Es un tópico decir que debemos partir de los intereses de los niños y niñas en estas edades. Creemos que la cuestión está mal planteada. Debemos partir de sus necesidades, de lo que es imprescindible para su desarrollo y crecimiento. Hay que tener una "oreja verde”, que decía Rodari, para saber interpretar qué necesitan y darles respuestas en las escuelas. Los chicos y chicas del aula de infantil pueden demandar trabajar sobre los juguetes, sobre un perrito que está enfermo, sobre las princesas o sobre los guerreros. Pero en el piso de abajo, como lo llama Mari Carmen Díez, se les está moviendo sus corazoncitos, sus emociones o sus necesidades, que salen a flote para que sean sanadas. Podemos trabajar sobre sus intereses porque debajo de estos, siempre emergen sus necesidades. En cualquier tema siempre surgen sus emociones: los celos, el amor, el miedo, la muerte... Estos contenidos están latentes en los cuentos, en sus conversaciones, en sus demandas, intereses y deseos. Sólo deberemos tener una "oreja verde" para detectarlos y trabajar sobre ellos.

Otra manida discusión en esta etapa educativa es si el profesorado debe establecer unas relaciones de amistad con el alumnado o ser fuente de autoridad. Los niños y niñas necesitan referentes adultos que los contengan y que les de seguridad y amor. Las dos cosas al mismo tiempo. Es necesario empatizar con ellos, entrar en sus juegos y tener cierta complicidad, y sólo desde ese lugar de conexión podemos ejercer de autoridad. La disciplina como técnica no funciona. En educación establecemos relaciones humanas y debe haber cariño y conexión para que haga efecto la contención y el límite. La principal capacidad que debe tener la per- 


\section{H I S T O R A S M ÍN I MA S}

\section{"Evaluar es comprender para mejorar. (...)Lo demás es culpabilizar, someter, controlar y legitimizar."}

sona educadora quizás sea conectar con la infancia sin perder nuestro lugar como adultos referentes.

Otra de las cuestiones controvertidas de la Educación Infantil es cómo lidiar con las programaciones y el currículum frente a las necesidades de la infancia. Se supone que el currículum es la especificación de lo que necesitamos saber para vivir. Las normativas educativas intentan plasmar esos contenidos pero han perdido la finalidad. Lo esencial que debemos aprender es lo que somos junto a los demás seres vivos, que estudia las Ciencias de la Naturaleza, lo que hemos sido hasta nuestros días, que lo estudia La Historia y en qué mundo vivimos, que lo trata la Geografía física, humana y económica. También es importante cultivar las artes, que es la máxima expresión creativa que hicimos como humanos. Y todo ello con los instrumentos que tenemos para pensar, conceptualizar y comunicar, que nos presta la Lengua, las Matemáticas o la Filosofía. Pero hemos dividido todo el contenido en porciones y lo hemos repartido en temas de libros de textos. Y pensamos que dando diariamente un trocito de conocimiento se juntarán en la cabeza de los chavales. Pues estamos equivocados. Los aprendizajes solo son relevantes si están globalizados, contextualizados y son funcionales. Y en la Educación Infantil debemos ir a lo esencial como resumió La Unesco hace tiempo: descubrir lo que somos, comprender a los demás y aprender el mundo en qué vivimos.

Y por último, subrayar el siempre problemático tema de la evaluación en Educación Infantil. Evaluar es comprender para mejorar. Me lo enseñó mi maestro Miguel Ángel Santos Guerra. Lo demás es culpabilizar, someter, controlar y legitimizar. Evaluar tiene sentido si sirve para entender a cada niño y niña: saber lo que les pasa, en qué situación están, que saben, qué necesitan y en qué les podemos ayudar. Sólo un buen diagnóstico sirve para educar. No debemos perdernos entre números cargados de supuesta objetividad. Los números sólo tranquilizan nuestras conciencias porque su simplicidad tiene visos de verdad. Lo dicho, evaluar es comprender para dar respuesta a las necesidades de la infancia, no hay más. 